\title{
Problems of Speech and Communication in the Works of Central Asian Philosophers
}

\section{Zamirbek Bozhonov로 Altynbek Kuduev², Dilzatbek Zholdoshbaev¹, Zhypargul Abdykalyk kyzy³, Boris Shumilov", Zhypargul Abdullaeva ${ }^{* *}$ (i)}

\author{
${ }^{1}$ Department Pedagogics and Phycology, Osh State University, Osh, Kyrgyzstan \\ ${ }^{2}$ Department of Technical Sciences, Osh State University, Osh, Kyrgyzstan \\ ${ }^{3}$ Departent of Law and Work, Osh State Jurisprudence Institute, Osh, Kyrgyzstan \\ ${ }^{4}$ Departent of Physics and Mathematics, Tomsk State Technical University, Tomsk, Russia \\ ${ }^{5}$ Science and Research Department, Osh State University, Osh, Kyrgyzstan \\ Email: ^jypar.science@oshsu.kg
}

How to cite this paper: Bozhonov, Z., Kuduev, A., Zholdoshbaev, D., Abdykalyk, Z., Shumilov, B., \& Abdullaeva, Z. (2020). Problems of Speech and Communication in the Works of Central Asian Philosophers. Open Journal of Modern Linguistics, 10 794-803.

https://doi.org/10.4236/ojml.2020.106049

Received: October 20, 2020

Accepted: November 29, 2020

Published: December 2, 2020

Copyright (c) 2020 by author(s) and Scientific Research Publishing Inc. This work is licensed under the Creative Commons Attribution International License (CC BY 4.0).

http://creativecommons.org/licenses/by/4.0/

\begin{abstract}
This article is analyzing problems of speech and communication in the works of Central Asian philosophers in the middle ages through language. In the mental life of a person, the speech performs many important functions. These include notation of functions, generalization, abstraction, communication, and related impact and expression. Interest in the problem of communication and speech has its roots from ancient times. This problem has always attracted researchers' minds, in particular, the great thinkers of Central Asia in the middle ages, who observed, analyzed, and explained the processes of relationship, mutual understanding between people, their interaction from the time when an immemorial man faced when encountering others. The works of medieval scholars of Central Asia including Al-Farabi, Al-Beruniy, Ibn Sina, Omar Khayyam, Yusuf Balasagyn, Ahmet Yagnaki consider the concepts of speech and communication, their functions, the relationship with language and thinking, the origin of language and speech, speech properties of the individual, speech culture, etc.
\end{abstract}

\section{Keywords}

Speech, Communication, Thinking, Culture of Speech, Training, Education

\section{Introduction}

Successes of modern psychological science are due to tremendous achievements in the development of society resulted in persistent purposeful works of many scientists generations and thinkers who strove for a more perfect knowledge of 
the world and the results of the evolutionary development in science.

Among them, we recall with a sense of pride and respect the names of medieval Central Asian scholars, who made a significant contribution to the development of world science and culture. They are Abu Nasr Al-Farabi, Al-Khorezmi, Abu Reikhan Berunyi, Ibn Sina, Yusuf Balasagyn, Mahmud Kashgari, and many others, whose scientific heritage is increasingly attracting the attention of scientists over the past centuries.

The concepts of "speech" and "communication" are inextricably linked, and they are used in a similar meaning sometimes (Ruqaiya, 1992; De Stefani \& De Marco, 2019; Wagner et al., 2014). Communication is understood as a multifaceted process of developing contacts between people, generated by the needs of joint activities.

And speech is a process of communication and conversation through language (Pardo et al., 2010). In the mental life of a person, speech performs several important functions. These include the functions of designation, functions of generalization, abstraction, communicative function, and related functions of influence and expression.

Interest in the problem of communication and speech has its roots in ancient times. This problem has always attracted the minds of people, in particular, the great thinkers of Central Asia of the Middle Ages, who observed, analyzed, and explained the processes of relationships, mutual understanding between people, their interactions, with which from time immemorial a person came into contact with others. In the works of medieval scientists from Central Asia, the concepts of speech and communication, their functions, the relationship with language and thinking, the origin of language and speech, the speech properties of the individual, the culture of speech, are considered.

The relevance and significance in this study characterizing views of Central Asian thinkers on speech and communication showed correct understanding of speech in the cognition and understanding of the surrounding world. It is influencing geographical factors, the need for the origin of language, relationships between speech and thinking, and the culture of speech. However, due to socio-economic relations, they did not rise to understand the role of labor, the need for the origin of language.

Rationality of choosing the thinkers of Central Asia, is related to their ideas about speech and communication, which is playing a large role in further development of materialistic ideas about speech in science, in the fight against the ideology of orthodox Islam. Although they did not rise to the Marxist understanding of the origin of language and speech.

\section{Farabi's Works}

Farabi's views on speech and communication are reflected in his scientific works on logic "A book on the art of writing", "A book on words and letters"; "On the beginnings of the existence of forms and accidence", "Speeches used in logic", "Introductory treatise to logic", etc. 
In his book "On the beginnings of the existence of forms and accidents", he gives a detailed description of speech: "Soul forces, which are human principles, for example, the following: speaking force, striving force, imagining force, feeling force."

Further, the scientist noting the important role of the speaking force in human life wrote: "The speaking force is such a force with which a person masters knowledge and craft, distinguishes the beautiful from the ugly in action and behavior, implements what is necessary, and does not what is not needed distinguishes useful from harmful, etc." (Al-Farabi \& Muhammad, 1973).

It should be specially noted that Farabi understood speaking power (kuvvan notika) not only speech but also thinking, thinking power (kuvvai fikriya). The thinker believed that all other psychic forces obey and serve the power of the speaker, and it plays a big role in a person's knowledge of the world around him, in teaching, raising children, improving personality, etc.

In the classification of sciences, Farabi assigns the science of language in the first place. "The science of language for every nation has seven major subsections, the science of simple words and the science of phrases, the science of the laws of simple words and the science of the laws of phrases, the laws of writing (spelling) and orthoepies, the rules of versification" (Al-Farabi, 1970).

A scientist expressed a bold idea on the issue of differences in the languages of peoples. He wrote: "One nation differs from another in three natural things: natural disposition, natural traits (character) and the third, based on the character (of people), which also has something to do with natural things. It is a language, i.e. speech, which is a means of expression (thought)" (Al-Farabi \& Muhammad, 1973).

On the other hand, Farabi saw the reasons for the emergence of differences in the languages of peoples in their disunity, its dependence on the geographic environment: the difference in the parts of the sky at the zenith of certain peoples: water, air, plants, various species of animals and the nutrition associated with them, etc. (Al-Farabi \& Muhammad, 1973).

Farabi sees a close relationship between speech and thought (objects of logic) processes. "There is no longer a path to true certainty in anything, to the knowledge of something without the art of logic. Its name 'mantic' comes from the word 'nutk-mind, speech"' (Al-Farabi, 1970).

The scientist rightly believed that speech and the associated art of logic would play an important role in the acquisition of knowledge. He gives an enormous role to internal and external speech in this process, pointing out, "...firstly, the ability through which a person thinks in categories, masters the sciences and arts, and also distinguishes between the beautiful and the ugly in his and others' actions; secondly, on the categories that arise in the human soul and are called internal speech, thirdly, on the expression of what takes place in the mind-this is called external speech. This art, since presents to the mind the rules of internal speech, which are common to all languages, and the rules of external speech, which make up linguistic expressions, directs the mind through them and in 
both cases warns against mistakes, is called logic" (Al-Farabi, 1970).

Al-Farabi, in his writings, draws attention to such speech properties of a person as wit, jokes, etc. Wit, according to the thinker, “...this is a good moral quality, arises with the moderate use of a joke" (Al-Farabi, 1970). Talking about the relationship between joke and wit, he writes, "A joke is one that, in its abundance, its enjoyable, or at least painless. The middle in a joke gives wit, excess leads to buffoonery, and lack of it leads to lack of (humor). A joke manifested in what a person says does or uses. Measure in it is what befits a free, cheerful, sociable person to speak and listen" (Al-Farabi, 1970).

The thinker's ideas about speech and communication positively influenced the development of scientific thought on this issue in subsequent centuries. For example, the "Encyclopedia" of the secret philosophical union of the "Brothers of Purity" emphasizes that "...communication (of people) is of two kinds: communication for food and drink, play and fun and body enjoyment with animal flesh and terrestrial plants, for the welfare of the changeable, destroying the perishable body. Communication for the sake of knowledge, wisdom, spiritual conversation gives pleasure to the soul, the substance of which does not perish and whose joys do not stop in an eternal refuge" (Akhvlediani, 1960).

\section{Beruniy's Works}

Beruniy's statements about speech are interesting. One of the powerful means of cognition, in addition to the senses, the mind, he considered speech, which "is ... an expression of the meaning that pursues the speaker" (Belenitsky, 1963).

Speech makes it possible to cognize the essence of objects and phenomena of the world around us. "A person has the gift of speech, can assess the essence of objects and phenomena" (Al-Berunyi, 1963). The emergence of differences in languages between peoples (nations) and nationalities, he explained primarily by geographical factors. "Differences in languages (associated) only with the division of people into peoples and their remoteness from each other" (Al-Berunyi, 1959).

This idea of Berunyi was very valuable in the Middle Ages when the existing religious teaching explained the differences in languages between peoples by the power of Allah.

The scientist saw the emergence of differences in languages between nations, a geographical factor in the process of the origin of a language in the needs of a person living in society. "Every nation needs common phrases, with the help of which people could express various desires" (Al-Berunyi, 1959). Here he discards the religious legends about the creation of languages by God. The origin of language is a process, not something given; over time, these expressions have been multiplied and ordered into common phrases. And the process of the emergence of writing Berunyi is considered from social needs.

Berunyi's thoughts on recognizing the social nature of speech were also shared by Kay Cavus, the author of the well-known book of an edifying nature "While 
you can, do not turn away from listening, for people acquire the gift of speech by listening to speeches. And the proof of this is that if they remove the child from the mother, and carry it into the dungeon and feed it with milk, and bring it up there, and neither the mother nor the nurse will talk to him and caress him, and he will not hear anyone's speeches, he will grow up he is dumb" (Bertels, 1958). On the other hand, Kay Cavus emphasizes that for the appearance of speech in children, the activity of the auditory sense organ plays the main role. “... anyone who is deaf from a mother is not new. Can't you see that the dumb are deaf" (Bertels, 1958).

According to Berunyi, speech is closely related to thinking, therefore it is one of the main tools of logic "Since a person is endowed with the gift of speech and entered into disputes and debates with his opponents on worldly and religious issues, he needed a 'scale' for his speech, so that check it on them and correct it with their help in case of unsteadiness (approved); after all, speech by its nature is capable of containing both truth and lies, syllogisms made up of words during disputes are accessible to the influence of both deception, misleading, and clarifying the truth. The man got these 'scales'. They are called logic. 'Grammar has become a true measure, correcting mistakes in speech, presented in prose, and prosody in verse"” (Al-Berunyi, 1995).

Recognition of the role of needs in the origin of the language, and the geographical factor, i.e. "The remoteness of peoples from each other", in the emergence of a variety of languages this is a wonderful guess Berunyi, who had progressive religious teaching in the Middle Ages.

Berunyi, like other thinkers of Central Asia, exalts the speech properties of a person: truthfulness, eloquence, and condemns liars. "Only one who avoids lies and adheres to the truth is worthy of approval and praise." After all, it said: "Speak the truth, even if it is against you" (Al-Berunyi, 1995). Condemning liars, he noted that a liar deviates from the path of justice and prefers to lean towards violence, perjury, violation of fidelity, seizure of other people's property by deceit, theft, and other vices from which the rest of the world and the human race originate. Talking about eloquence. Berunyi wrote that eloquence has magical power.

Man is a rational being, has spoken, but he differs from animals and improves his actions. It is thanks to speech and communication that a person satisfies his needs, exchanges opinions, influences each other, he has a desire to achieve a goal, there is a desire to improve even more.

\section{Works by Ibn Sina}

Ibn Sina's views on the anatomical and physiological mechanisms of speech are revealed in his book "Mahgrej-al-Haruf" ("The Reasons for the formation of Speech Sounds"), dedicated to the phonetics of the Arabic language. It has six sections. The first two and the last three are devoted to the disclosure of the cause and the formation of the sounds of Arabic and some other languages. And 
the third section reveals the anatomy of the tongue and larynx (Zakuev, 1961).

Communication between people is done for the sake of satisfying their needs, for the sake of mutual assistance to each other. "A person is not isolated." Ibn Sina wrote, -in the sense of independence of his personal needs since he can satisfy them only in communication with other representatives of the human race.

"In the processes of exchange and interdependence that are established between people, each relieves the other of any concern, while if each did everything himself, too heavy and hardly feasible burden would fall on his shoulders" (Ibn Sina, 2005).

To satisfy their human material needs, people must work, they need communication and mutual assistance, and language and thinking serve people for communication.

Ibn Sina's statement about the role of the need for communication, although not fully scientifically substantiated, the postulated thesis gives us a sufficient idea that the thinker recognized the social nature of the individual.

In the history of science, the classics of Marxism-Leninism scientifically substantiated the problem of the development of a social person not only inactivity but also in communication. "The production of ideas, perceptions, and consciousness is initially directly interwoven into material activity and material communication of people, into the language of real life. The formation of ideas, thinking, spiritual communication of people is here still a direct product of the material relationship of people" (Marx \& Engels, 1983).

Ibn Sina in his book "Healings" reveals in detail the problem of the relationship between language and speech. The views of the thinker on this issue are as follows: a person expresses his concealment of thought through language, without words he cannot express his thoughts. In a word, a person, in the process of communication, expresses communicated thoughts through the appropriate language, and he cannot speak without language, cannot make a judgment, a conclusion.

Language is a mental sign and a means of communication.

The thinker's statements about the influencing function of speech, that is, on the human psyche, on his emotions and feelings, are interesting.

This function of speech will play an important role in educational, medical work. According to Ibn Sina, rash speech can negatively affect human health. Therefore, one of the factors in maintaining human health. Therefore, one of the factors in maintaining health is: not to communicate with just anyone. On this occasion, the scientist expressed his opinion in the book "Firuznome" in the form of a dialogue between the thinker and himself.

\section{Works by Omar Khayyam}

Speaking about the role of written speech, Omar Khayyam wrote: "A person who owns the dignity of speech but does not possess the dignity of writing, is imperfect and looks like half a person, since the dignity of writing is great, and 
no dignity is equal to it, it raises a person out of the degree man to the degree of an angel, and the devil from the degree of the devil to the degree of man. Writing raises a person from a low level to a high level, such that he is called a scientist, imam, Islamic jurist, and secretary, just as people with the dignity of speech differ from other animals and become their leaders" (Khayyam, 1961). The scientist attached great importance to the culture of speech. A person should not be many-speaking, but low-speaking, stingy in speech:

"Do not shout about the secrets of the ignorant

And beads of valuable knowledge are not swords before the fool.

Be sparing in your speeches and the first look at whom you are talking to:

Cherish your hopes, but hide the keys from them" (Khayyam, 1961).

And here is another quatrain where the philosopher's stone is laid:

“To live life wisely, you need to know a lot,

Remember two important rules to start with:

You better starve than eat anything

And it is better to be alone than with just anyone" (Khayyam, 1961).

\section{Yusuf Balasagyn Works}

Yusuf Balasagyn also attaches great importance to communication, the culture of speech. It is the culture of speech that determines the level of cognitive, mental, and moral maturity of the individual. Each person acquires knowledge from other people precisely in communication through language. Emphasizing the importance of language as a means of communication and the acquisition of knowledge. Yusuf Balasagyn wrote:

"Language is the translator of science and knowledge,

The language bestows radiance on a person" (Balasagyn, 1983).

In his opinion, with the help of speech, as you know, you can evoke in other people a feeling of joy, anger, inspiration, stimulate the aspirations and actions we need: "Frowning face, angry speech freezing,

Their poison remains in the soul forever.

There is a correct verse about this, do not forget

The very essence is captured in it:

Branching word and spiteful speech

Like a flame in the soul, and like a sword for the body.

And grave wounds are given to heal,

And malice is given to burn endlessly!” (Balasagyn, 1983).

Of considerable interest are the statements of the scientist about written speech, which is of great importance in improving culture, assimilating knowledge, mental development, acquiring social experience, etc. The level of mastery of writing is one of the signs of a person's mental development.

In connection with the above statements of Yusuf Balasagyn about the little talk, the following question arises: why did Yusuf Balasagyn, and indeed all Central Asian thinkers of the Middle Ages in their works, glorify little talk as one of 
the important personality traits? In our opinion, a person of few words, who does not like to throw words into the wind, compares favorably with people who are chattering. As you know, laconic and outwardly reserved people are often highly respected both in the family circle and among close people, workmates, etc. That is why progressive thinkers of the East in their writings exalt little talk.

Central Asian medieval thinkers lived and worked in a feudal society, being its representatives. Therefore, in their views on the problem of speech and communication, a social portrait of their time appears as realistic colors. Theft, bribes, gossip, deceit, slander, etc. develop. Here a person must keep many things in secret, keep his tongue from an unexpected word, otherwise, teeth will break or every word will have to answer with his head. They warn people.

\section{Ahmet Yagnaki Works}

And another Central Asian thinker Ahmet Yagnaki (born at the end of the 12th century in the city of Yugnaki, near Samarkand) in his book "Khibatul Khakaik" ("Gift of Truth") attached great importance to communication in human life, the culture of his speech. On the one hand, in a progressive spirit, he approves of the speech properties of a person: sociability, politeness, modesty, truthfulness, and on the other hand, criticizes talkativeness, megalomania, inappropriate speech, etc. Ahmet Yugnaki, like Yusuf Balasagyn, believed that morality, knowledge, man's mind. Therefore, he indicates the main thing in morality language, and you need to restrain it.

The poet, in his edification, gives the young advice that they should be restrained, laconic, prudent, and careful in speech. Every word of a person should be thoughtful, appropriate, whatever happens to a person, everything bears the traces of his language. Because of its use, some people experience happiness and some people experience unhappiness.

He urges people to beware of backbiting so that it negatively affects human health, can hurt more painfully than any weapon: "Do not make people feel revenge with your tongue, know this language, if it hurts, the wound does not heal, but the arrow will heal."

Ahmet Yugnaki makes fun of talkativeness and deceit, says that two personality traits, uniting in one person, lead him to trouble:

"One thing, if he chatters unnecessary words,"

"It is different if the tongue of that husband is lying."

He gives the young the following advice, "Keep yourself away from a liar, live your life with honesty" (Yugnaki, 1971). The views of Central Asian thinkers on speech and communication show the correct understanding of the meaning of speech in the cognition of the surrounding world, its influencing functions, the role of the geographical factor, needs in the origin of language, the relationship between speech and thinking, and the culture of speech. However, due to socio-economic relations, they did not rise to understand the role of labor, the need for the origin of language. 
In the history of science, only the classics of Marxism-Leninism have positively resolved this issue. In this regard, F. Engels wrote: “... the people who were forming concluded that they needed to say something to each other. The need created its organ: the undeveloped larynx of the monkey was slowly but steadily transformed by modulation for more and more developed modulation, and the organs of the mouth gradually learned to pronounce one articulate sound after another" (Marx \& Engels, 1983).

\section{Conclusion}

As for the thinkers of Central Asia, although they did not rise to the Marxist understanding of the origin of language and speech, their ideas about speech and communication played a large role in the further development of materialistic ideas about speech in science, in the fight against the ideology of orthodox Islam. The ideas about the culture of speech have especially not lost their significance until now: eloquence, truthfulness, politeness, propriety, the reasonableness of the word. These ideas were of universal human value and are consonant in our days in the education of youth.

Practical implications in this study are implying ideas of the culture in speech including eloquence, truthfulness, politeness, appropriateness, and reasonableness of the word. These ideas had universal human value and are consonant in our days and in young people's education.

\section{Conflicts of Interest}

Authors declare no conflict of interest regarding the submission of this article.

\section{References}

Akhvlediani, V. G. (1960). Avicenna's Phonetic Treatis (pp. 1, 8). Tbilisi: Mecniereba.

Al-Berunyi, A. (1959). Monuments of the Past Generations (p. 1). Tashkent.

Al-Berunyi, A. (1963). Mineralogy (524 p.). Leningrad: Publishing House of the Academy of Sciences USSR.

Al-Berunyi, A. (1995). India (Translators: Khalidov, A., Zavadovsky, Y., Erman, V., 727 p.). Moscow: Ladomir.

Al-Farabi (1970). Philosophical Treatises (429 p.). Alma-Ata: Nauka.

Al-Farabi, \& Muhammad, A. N. (1973). Socio-Ethical Treatises (400 p.). Transl. from Arabic, Alma-Ata: "Science" of the Kazakh SSR.

Balasagyn, Y. K. H. (1983). Blessed Knowledge (Translated by Ivanova, S.N., 560 p.). Moscow: Nauka.

Belenitsky, A. M. (1963). Berunyi Abu Reikhan (519 p.). Geodesy. Academy of Sciences of the USSR.

Bertels, E. E. (1958). Kabus-Name Article and Notes (2nd ed., 299 p.). Moscow: Science.

De Stefani, E., \& De Marco, D. (2019). Language, Gesture, and Emotional Communication: An Embodied View of Social Interaction. Frontiers in Psychology, 10, 2063. https://doi.org/10.3389/fpsyg.2019.02063

Ibn Sina (2005). A Treatise on Ethics (pp. 739-753). Compositions. Dushanbe: Academy 
of Sciences of Republic Tajikistan.

Khayyam, O. (1961). Treatises (Translation: Yushkevich, A.P., 338 p.). Moscow: Eastern Literature Publishing House.

Marx, K., \& Engels, F. (1983). Selected Works in 3 Volumes. Moscow: Progress Publishers.

Pardo, J. S., Jay, I. C., \& Krauss, R. M. (2010). Conversational Role Influences Speech Imitation. Attention, Perception, \& Psychophysics, 72, 2254-2264. https://doi.org/10.3758/BF03196699

Ruqaiya, H. (1992). Speech Genre, Semiotic Mediation and the Development of Higher Mental Functions. Language Sciences, 14, 489-528. https://doi.org/10.1016/0388-0001(92)90027-C

Wagner, P., Malisz, Z., \& Kopp, S. (2014). Gesture and Speech in Interaction: An Overview. Speech Communication, 57, 209-232. https://doi.org/10.1016/j.specom.2013.09.008

Yugnaki, A. (1971). Hibatul Hakaik (p. 47). Tashkent.

Zakuev, A. K. (1961). Philosophy "Brothers of Purity" (122 p.). Baku: Publishing House Acad. Sciences AzSSR. 